\title{
Erratum to: Evaluation of clinical bradycardiac effect and respiratory adverse effect of $\beta$-blocking agents in coronary computed tomography angiography based on theoretical analysis
}

\author{
Kaori Fujito $^{1} \cdot$ Risa Takayanagi $^{1} \cdot$ Koji Kimura $^{1} \cdot$ Haruko Yokoyama $^{1} \cdot$ \\ Yasuhiko Yamada ${ }^{1}$
}

Published online: 18 September 2015

(c) Springer International Publishing Switzerland 2015

\section{Erratum to: Eur J Drug Metab Pharmacokinet DOI 10.1007/s13318-014-0244-3}

A Published-Ahead-of-Print version of this article was made available online on 16 Dec 2014. An error was subsequently identified in the original version of the article, and the following correction should be noted:

Figure 4: there was an error in the Esmolol graph, the correct figure should appear as follows:

The online version of the original article can be found under doi:10.1007/s13318-014-0244-3.

Yasuhiko Yamada

yamada@ps.toyaku.ac.jp

1 Department of Clinical Evaluation of Drug Efficacy, School

of Pharmacy, Tokyo University of Pharmacy and Life

Sciences, 1432-1 Horinouchi, Hachioji, Tokyo 192-0392,

Japan 

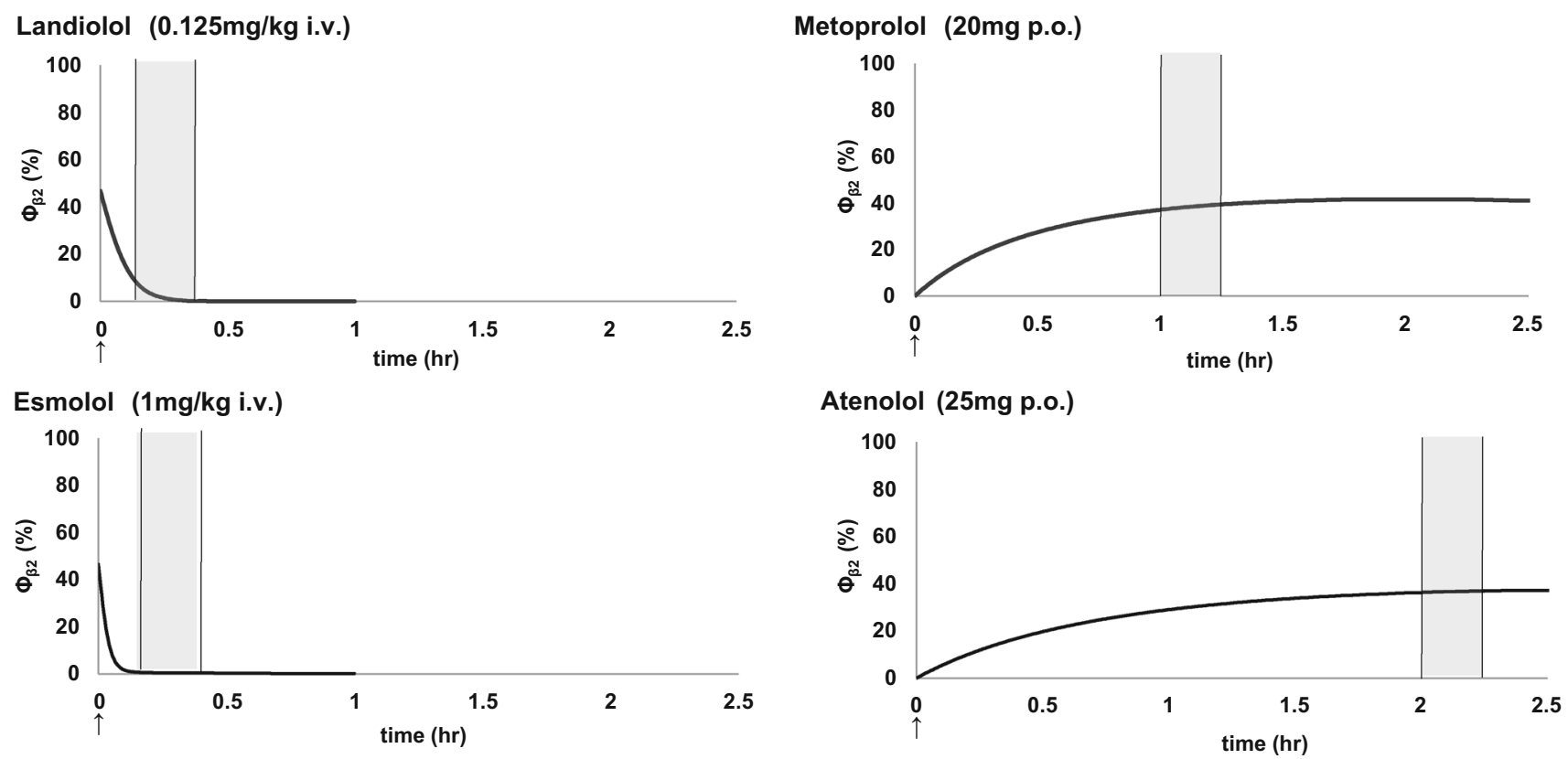

Propranolol (2mgi.v.)

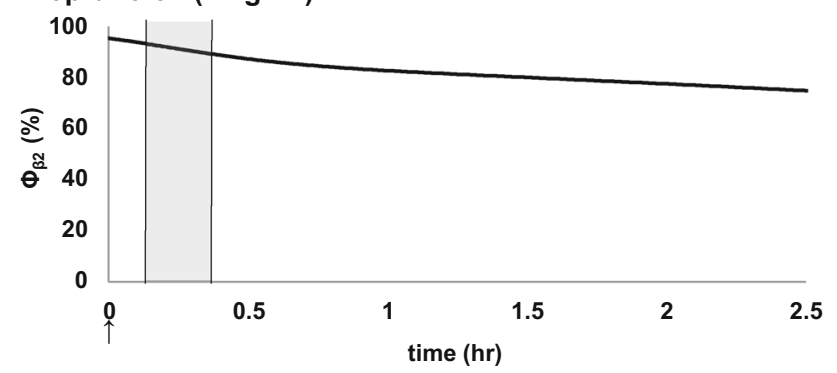

Fig. 4 Time-courses of $\beta_{2}$ receptor occupancy $\left(\Phi_{\beta_{2}}\right)$ of five $\beta$-blocking agents after intravenous or oral administration for use with CCTA (i.v. intravenous administration, p.o. oral administration, upward arrow taking each drug at $0 \mathrm{~h}, \mid$ | examination time period of CCTA) 